\title{
THE SIMULATION ANALYSIS OF CRUISE ROUTE PLANNING
}

\author{
Ling Sun \\ Shanghai Maritime University, P.R.China \\ Huangming Xie \\ Shanghai Maritime University, P.R.China \\ Hanwen Zhang \\ Shanghai Maritime University, P.R.China \\ Wei Liu \\ Shanghai Maritime University, P.R.China
}

\begin{abstract}
With the rise in popularity of the cruise market, several schemes and procedures are planned in order to cater for this advancement. Mainly, this paper demonstrates the principal approaches towards constructing plans for designing cruise routes. First and foremost, each port is ranked according to its attractiveness under four indexes, namely marine services, customs clearance services, transport services and tourism services. Secondly, with the aim of creating asymmetric links and the shortest path, a planning model is formulated to select and rank the ports of call. The aim of the model is to gain the optimal revenue per voyage, with considerations of time window and voyage duration. With regards to small-scale and large-scale port collections, the traversal and randomised algorithms are adopted to find the practical routes. Furthermore, an empirical analysis of routes in South Asia is given. Above all, this paper aspires to aid future route planning and unleash increased potential in consumer markets.
\end{abstract}

Keywords: cruise ship; route planning; asymmetric links; shortest path; simulation

\section{JEL code: L920}

\section{Introduction}

The modern cruise industry originated from the late 1860s and early 1870s (Rodrigue and Notteboom, 2009). In recent years, this industry has gained popularity in the modern touristic sector for its stable growth rate of about $8 \%$, naming this industry 'the golden industry floating in the golden waterway'. The cruise ship has high multiplier effects, strong adsorption capacity and driving ability to promote the rapid economic growth in the surrounding areas of the port. Also, sightseeing on shore can as well promote a rapid economy development.

With these efficiencies, several countries have started constructing national cruise ports. As these new home-ports have limited routes, their attraction to secondary tourists is as well limited, with few systematic researches of cruise routes. Focusing on cruise route planning, this paper indulges in profound studies relating influential factors and considerations of various variables, correlating with the act of designing valuable cruise routes. We hope this paper can contribute to developing more practical routes, attracting more tourists and improving the usage rate of home-ports. 
After surveying literatures, we found that the quantitative and qualitative analyses are of the same importance in the field of route planning. Quantitative analysis refers to building mathematical models, considering influencing factors in actual operation process, implementation and optimisation. On the other hand, qualitative analysis studies and explores the problems which fail to transform into mathematical models. Overall, the goal of this paper is cruise route planning. However, in the whole cruise industry, there are actually few studies focusing on this topic. Therefore, this paper will refer to relatively mature methods of router shipping network design and optimisation. We adopt the simulation model in Matlab, calculating the attractiveness of different ports by AHP Method, planning the routes with the simulation model, making regression fitting of cruise tickets and finding a possibility for routes with an optimal voyage profit.

Judith and Rommert (2014) studied on the problem of design of the shipping route network under the condition of the given number of ships, mainly including fleet design, scheduling and shipping route; Berit et al. (2014) proposed similar solutions for the shipping network design and fleet scheduling of an ocean liner shipping company; Dong et al. (2015) studied on joint transportation planning and dynamic route selection of the router shipping network and established a two-stage randomised programming model; R. Aversa et al. (2015) took a minimum cost of the total system as the target value to select a transit port for four kinds of container types in the import and export transportation network; Christian et al. (2016) studied multi-commodity flow problems and solved these problems by column generation algorithm under the given transit time limit.

Combined with the above literatures, this paper draws the conclusion that the route planning problem is mainly composed of selecting ship types and establishing ports of call and routes. First of all, we evaluate the alternative ports which involve various factors, and also analyse the four aspects that are made up of marina services, transport services, customs clearance services and tourism services. Using fuzzy comprehensive evaluation based on AHP to evaluate the ports, we can obtain the estimation and ranking of each port. Secondly, based on the principle of asymmetric links and the principle of shortest path and maximum flow, the establishment of practical routes can be obtained by the MATLAB modelling. As to small-scale and large-scale ports collection, this paper will respectively adopt traversal algorithm and randomised algorithm to obtain practical routes.

\section{Port of call selection in cruise route planning}

\subsection{Index selection}

From the perspective of the cruise ship company, in order to choose better ports of call, this paper outlines the influence factors of port competitiveness combined with related literatures. The following factors are involved as shown (Barron and Greenwood, 2006) (Johnson, 2006) (Lekakou, 2009) (Lorenzo and Antonio, 2011).

Marina services: The marina should meet the requirements of tourists and cruise ships. For instance, anchorage, clearance, turning Basin, size of berths, channel depth, tidal range and pilot service are all important indexes.

Customs clearance services: Organisational processes of terminal and order arrangement at site have a direct influence on the visitors' experiences. Customs clearance services involve a clearance convenience, the staff's organisational capability and a baggage service. 
Transport services: Limited playing time on shore puts forward higher requirements to the schedule.

This paper regards the vehicle order management, the number of parking spaces on the wharf and the port hinterland accessibility as the main factors affecting the level of transport services.

Tourism services: A good natural environment not only provides tourists with scenery and a comfortable experience, but also acts as a necessary condition to carry out shore excursions. This paper regards the natural environment, the local tourism resources, the service quality of agency and the tourism support policies as the principal factors affecting tourism services.

\subsection{Evaluation method}

The selection of the cruise port should take both quantitative and qualitative indicators into consideration. In this paper, the designed routes are mainly focused on Chinese cruise market, and combine specifically with the situation at hand. Chinese cruise industry has only developed for not more than one decade. Also, the objective weight determination method cannot be adopted for the insufficient data. Thus, referring to Demirel and Yucenur (2011)'s cruise port's selection under the fuzzy environment, this paper will predominantly adopt the fuzzy comprehensive evaluation method based on the Analytic Hierarchy Process (AHP) to evaluate the alternative ports. This evaluation is divided into two steps. First, the weight should be calculated by means of the Analytic Hierarchy Process. Secondly, the optional schemes should be given by means of the Fuzzy Comprehensive Evaluation based on the Analytic Hierarchy Process. Taking the existing situation into consideration, the evaluation indexes are built (Fig1).

Here, the elements of the port selection are first classified by the Analytic Hierarchy Process. Then, the last layer of elements is regarded as the evaluated indexes. Afterwards, the software called Yaahp is adopted in calculation.

Moreover, there are three levels built in this paper. The top level is the ultimate purpose actually solved by model. The second level determines the indexes affecting the competitiveness of the ports, namely marina services, customs clearance services, transport services and tourism services. Then, the last level contains the detailed indexes which are determined according to literatures.

In the model, the judgment matrix is a positive reciprocal matrix built with all indexes. If there is $B_{i j}=B_{j k}=B_{i k}$ for any $i, j, k$, the matrix is consistent. In order to quantify the decision, the 1-9 sign method proposed by T. L. Saaty is adopted in weight determination.

In the first step, the factor sets of evaluated objects are established. It is assumed that evaluated objects have $\mathrm{m}$ evaluation indexes. Each alternative port has four kinds of evaluation indexes. Therefore, $U=U_{1} \cup U_{2} \cup U_{3} \cup U_{4}, U_{1}=\left\{\begin{array}{ll}u_{i 1}, & u_{i 2}, \ldots u_{i s}\end{array}\right\}, U_{i} \cap U_{j}=\varnothing$, $\forall i \neq j, i, j=1,2,3,4$.

In second step, the grade collection of evaluated objects is established. It is assumed that $V=\left\{v_{1}, v_{2}, \ldots v_{n}\right\}$. This means the overall potential evaluation results collection made by the 
experts. In this paper, there are four evaluation results, which are very obvious advantages, obvious advantages, generally obvious advantages and no advantages. Each grade represents one fuzzy subset.

In third step, the weight vectors of the evaluated factors are established. It assumes that $A=\left\{a_{1}, a_{2}, \ldots a_{m}\right\}$ is weight distribution fuzzy vector. $a_{i}$ is weight of the $i$-th factor and $a_{i}>0, \sum a_{i}=1$.

Then, the single factor fuzzy evaluation and fuzzy relation matrix are made. In this stage, the quantifying of evaluated objects on each factor $u_{i}$ is completed. Afterwards, the fuzzy relation matrix is determined in terms of membership $\left(R / u_{i}\right)$ of each grade fuzzy subset.

$$
\begin{gathered}
R=\left[\begin{array}{l}
R \mid u_{1} \\
R \mid u_{2} \\
\mathrm{~L} \\
R \mid u_{m}
\end{array}\right]=\left[\begin{array}{llll}
r_{11} & r_{12} & \mathrm{~L} & r_{1 s} \\
r_{21} & r_{22} & \mathrm{~L} & r_{2 s} \\
\mathrm{~L} & \mathrm{~L} & \mathrm{~L} & \mathrm{~L} \\
r_{m 1} & r_{m 2} & \mathrm{~L} & r_{m s}
\end{array}\right]_{m . s} \\
r_{i}=\left(\begin{array}{llll}
r_{i 1} & r_{i 2} & \mathrm{~L} & r_{i s}
\end{array}\right), \sum r_{i j}=1
\end{gathered}
$$

Among them, $r_{i j}$ represents a membership of evaluated object for hierarchical fuzzy subset $v_{j}$ on factor $u_{i}$.

Finally, the fuzzy comprehensive evaluation result vector should be compounded. This also means the completion of the multi-index comprehensive evaluation. The model is shown below:

$$
B=A \cdot R=\left(a_{1}, a_{2}, \mathrm{~L}, a_{m}\right)\left(\begin{array}{cccc}
r_{11} & r_{12} & \mathrm{~L} & r_{1 s} \\
r_{21} & r_{22} & \mathrm{~L} & r_{2 s} \\
\mathrm{M} & \mathrm{M} & \mathrm{M} & \mathrm{M} \\
r_{m 1} & r_{m 2} & \mathrm{~L} & r_{m s}
\end{array}\right)=\left(b_{1}, b_{2}, \mathrm{~L}, b_{s}\right)
$$

$b_{i j}$ represents the membership of evaluated objects for hierarchical fuzzy subset elements $v_{j}$.

\subsection{Weight results}

The survey data comes from 30 employees with more than a 5-year-experience in cruise companies, 20 employees working in a cruise tourism agency and 10 cruise tourism-related academic workers. This paper is about taking cruise route designing into consideration, with the calculation process of weights not elaborated. The results are shown in Figure.1. 


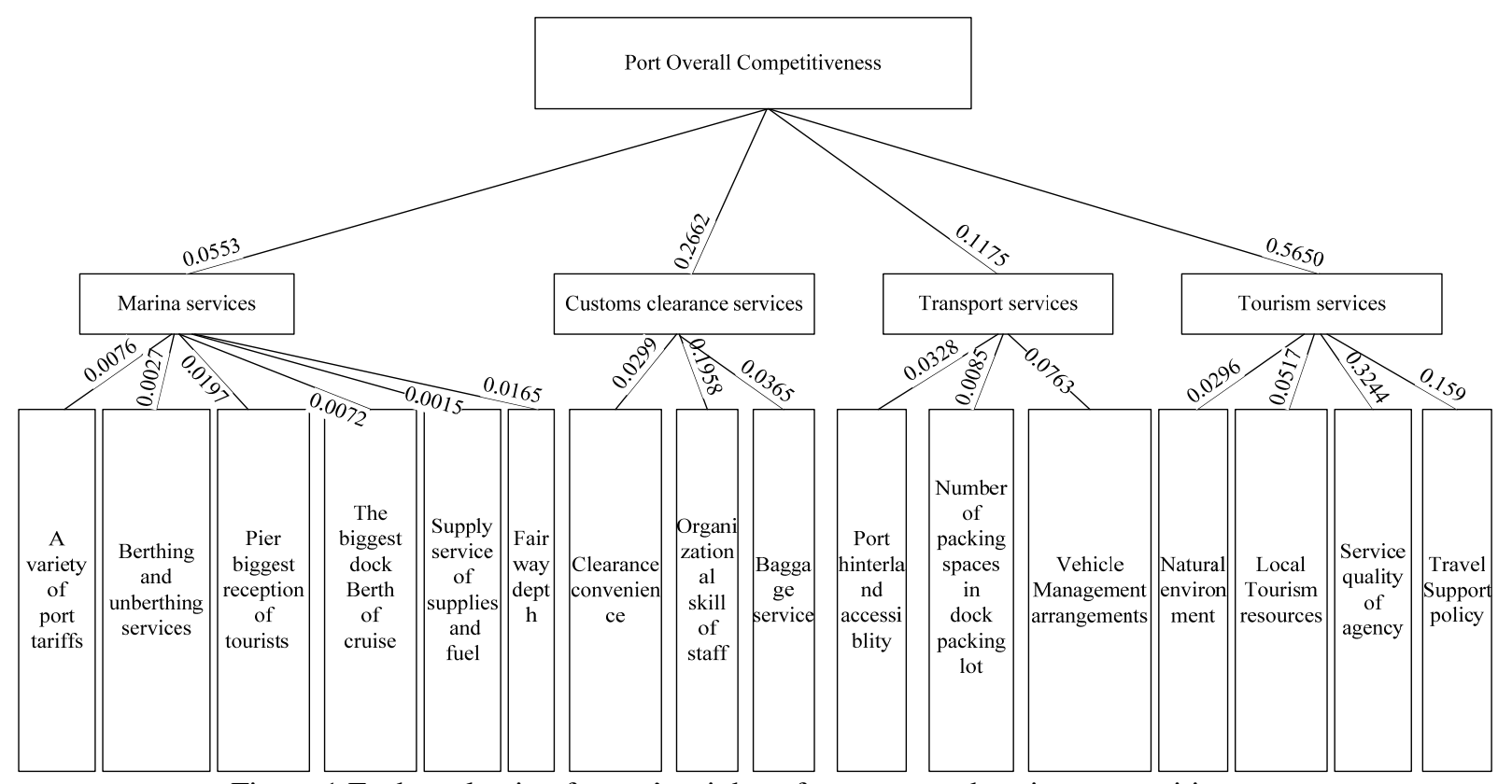

Figure.1 Each evaluation factors' weights of port comprehensive competitiveness

\section{Simulation model}

\subsection{Design Principles}

(1) Each route has one departure port and one destination port. This is a special characteristic of Chinese cruise market. On the contrary, in some international routes, the home-port and destination port are not the same.

(2) The selection of the port of call needs to consider various factors, namely, the depth of wharf, maximum tonnage and port charge, which are to be considered in the aspect of port location. Clearance convenience and organizing ability should be considered in the aspect of custom service. Moreover, parking space and traffic convenience should be considered in the aspect of transportation service. And, the travel agency, local scenery resource and tourism policy should be considered in the aspect of tourism service.

(3) The duration of cruise routes should be planned according to market rules. The voyage cycles can be classified to 5-6 days, 6-8 days, 9-16 days and even more than 16 days, to satisfy the various needs of customers.

(4) The arrangement of the voyage should meet the tourism demand. In general, the cruise travel can be divided into the entertainment on board and on shore. Thus, when the planning of the cruise routes is being formulated, it is necessary to ensure that tourists can travel to the destination port during day time and travel on board after departing the port at dawn or night.

(5) It is necessary to ensure the adequate fuel and supplies. After completing the last voyage, the cruise ship will get fuel and supplies at the departure port in the next voyage. Also, it can get fuel and supplies at the port of call with the lowest cost in the next voyage. Thus, in addition to ensuring that there is enough supply that meets the passengers' demands at departure port, the cruise company also needs to ensure that there is such a port of call that has the ability to provide supply services for the next voyage.

(6) The planning of cruise routes should avoid the repetition of ports of call. Furthermore, it is 
essential to ensure that the cruise ship can be affiliated to different ports as much as possible, so as to improve the attractiveness of the routes.

\subsection{Modelling}

In addition to considering the geographical factors of ports of call, hydrological conditions, tourism resources of port hinterland and cruise route planning, two other aspects must be taken into consideration -income and cost. According to particular data from annual reports of some cruise ship companies, the income of the cruise company comes from the tickets and all kinds of entertainment consumption consumed by passengers on the ship. Obviously, the income is mainly determined by the passenger capacity on the cruise ship. Furthermore, the costs are divided into fixed costs and variable costs. The fixed costs are commissions, transport costs, crew wage costs, marketing and administrative expenses. If the voyage lasts longer, there will be more cost. However, the duration of the voyage is determined by the number of port of call and speed. For the sake of ensuring a positive customer experience, it is more reasonable not to sail at full speed. Since the cruise port of call is under the constraint of the time window, MATLAB is used in this paper.

(1) Model assumptions:

The cruise route planning involves the geographical factors and the seasonal factors. The stability of hydrological and meteorological conditions is of great significance in navigation. For example, if there are fog and other interfering weather conditions during the voyage, on-shore recreation would be cancelled. This paper will not take the several hydro meteorological conditions' effects in cruise routes into account.

Moreover, the route planning does not consider any time differences. The time is subject to the departure port's time. Since cruise route planning is limited to the total voyage time, it does not have a significant impact on the planning results of the entire route.

On the basis of annual reports' data of some large cruise companies, the income is mainly generated from tickets and entertainment consumption on the ship. However, due to the large randomness of consumption, the cruise revenue mostly discussed in the paper is the ticket income.

In order to show the effects of route planning better, this paper will establish the ticket price by multiple linear regression and also establish voyage patronage as full cabin.

\section{(2) Symbol Description:}

In the cruise route planning problem of Maritime Silk Route, on the basis of the given departure port and total voyage time, affiliated ports and calling sequence should be established. Parameters are shown as below:

\begin{tabular}{|l|l|l|l|}
\hline$i, j \in N$ & Collection of alternative ports & $d_{s}^{s}$ & Total distance of cruise route \\
\hline$s \in S$ & Collection of cruise route & $d_{i j}$ & $\begin{array}{l}\text { Distance between port } i \text { and port } \\
j\end{array}$ \\
\hline$C_{s}$ & Total cost of cruise route & $v$ & Speed of selected ship type \\
\hline$C_{s}^{F}$ & Voyage fixed cost of cruise route & $T_{s}$ & Voyage time of cruise route \\
\hline$C_{s}^{V}$ & Voyage variable cost of cruise route & $T_{s}^{s}$ & $\begin{array}{l}\text { The total time on water on cruise } \\
\text { route }\end{array}$ \\
\hline
\end{tabular}




\begin{tabular}{|l|l|l|l|}
\hline$C_{s}^{o}$ & Voyage fuel costs of cruise route & $T_{s}^{t}$ & $\begin{array}{l}\text { The total time spent on ports of } \\
\text { call on cruise route }\end{array}$ \\
\hline$C_{s}^{h}$ & Voyage port charges of cruise route & $t_{i}$ & Anchored Time of each port \\
\hline$C_{s}^{l}$ & Voyage passengers' total living cost on cruise route & $a_{i}$ & Attractiveness index of port $i$ \\
\hline$C_{r 1}$ & Fuel rate used by sailing days & $A_{s}$ & Attraction of cruise route \\
\hline$C_{r 2}$ & Fuel rate used by affiliated ports & $R_{s}$ & Voyage revenue of cruise route \\
\hline$C_{c}$ & Diesel rates & $P_{s}$ & Ticket price of cruise route \\
\hline$C_{p i}$ & Port charges of port $i$ & $Q_{s}$ & The demand of cruise route \\
\hline$C_{l}$ & Living cost of each passenger & $D$ & $\begin{array}{l}\text { Maximal passenger capacity of } \\
\text { selected ship type }\end{array}$ \\
\hline$C_{f}$ & Fixed operating costs of each voyage day & $H_{A i}$ & Time to reach port of call $i$ \\
\hline$X_{i j}$ & $\begin{array}{l}\text { 0-1parameter; Whether the ship directly sails from port } \\
\text { to port whether there exists segment }(i, j)\end{array}$ & $H_{L j}$ & Time to depart the port of call $j$ \\
\hline
\end{tabular}

\subsection{Problem Description}

The cruise route planning actually involves three problems - the selection of ports of call, the sequence of ports of call and the route revenue management. Compared with the route planning problem in the shipping field, these all involve a selection of a ship type, the selection of ports of call and the establishment of calling sequence. This is not allowed in cruise transportation, except for departure port and destination port, in order to achieve the maximum possible revenue of single voyage. Besides the asymmetric links problem, cruise route planning also involves the ship's return. In order to provide a solution for ship return issues, while ensuring that voyage time is programmed within the time limit, this paper will assume that the departure port is the last port, so that the problem focuses on finding the shortest path and maximum flow.

Based on the above principle, the model is built. The departure port and destination port are the same cruise home-port. According to the above methods, the virtual port is established-the $(n+1)$ th port is the cruise home-port. By taking the maximum benefit of the cruise company as the objective function, this paper builds a mathematical model for route planning.

The objective function :

$$
\begin{aligned}
& \max f\left(c_{p i}, \sum_{i} \sum_{j} x_{i j} \cdot d_{i j}\right) \cdot Q_{s}-\sum_{i} c_{p i} \sum_{j} x_{i j}-c_{r 1} \cdot \frac{\sum_{i} \sum_{j} x_{i j} \cdot d_{i j}}{v \cdot 24} \\
& -c_{r 2} \cdot \frac{\sum_{i} t \sum_{i} x_{i j}}{24}-c_{c} \cdot \frac{\sum_{i} t_{i} \sum_{i} x_{i j}}{24}-c_{l} \cdot Q_{s} \cdot\left(\frac{\sum_{i} \sum_{j} x_{i j} \cdot d_{i j}}{v \cdot 24}+\frac{\sum_{i} t_{i} \sum_{j} x_{i j}}{24}\right) \\
& -c_{f} \cdot\left(\frac{\sum_{i} \sum_{j} x_{i j} \cdot d_{i j}}{v \cdot 24}+\frac{\sum_{i} t_{i} \sum_{j} x_{i j}}{24}\right)
\end{aligned}
$$

Constraint condition: 


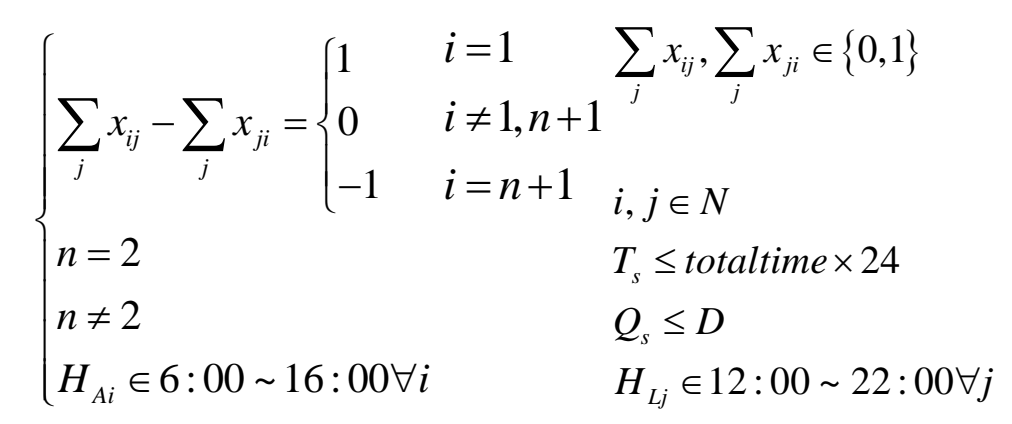

Whether to choose one port of call or another is one of the most important parts of route planning. This paper adopts the following methods to ensure that the cruise ship would not continuously anchor the intermediate ports. $\sum_{j} x_{i j}$ means how many ports have been anchored from the port $i$; $\sum_{j} x_{j i}$ means how many ports have been anchored from port $j$; when $i=1, \sum_{j} x_{j i}-\sum_{j} x_{i j}=1$ means that port $i$ is the departure port and the ship would not anchor the intermediate ports; when $i \neq 1, n+1 \sum_{j} x_{j i}-\sum_{j} x_{i j}=0$ means intermediate ports must both be the destination port and departure port; when $i=n+1, \sum_{j} x_{j i}-\sum_{j} x_{i j}=-1$ means port $i$ is the destination port and not the departure port. Although alternative ports are defined as $\mathrm{n}$, in order to improve the convenient degree of finding practical programs, this paper defines the departure port as the $(n+1)$ th virtual port, so that the route program can be successfully established by the method of shortest path and the maximal flow.

The corresponding voyage time of each cruise route includes the sea voyage time and the anchored time of each port. $T_{s}^{s}$ means the sea voyage time of the whole voyage, while $T_{s}^{t}$ means the anchored time of all ports of call in the whole voyage. Details are as follows:

$$
\begin{gathered}
T_{s}^{s}=\frac{d_{s}}{v}=\frac{\sum_{i} \sum_{j} x_{i j} \cdot d_{i j}}{v} \\
T_{s}^{t}=\sum_{i} t_{i} \cdot \sum_{j} x_{i j} \\
T_{s}=T_{s}^{s}+T_{s}^{t}
\end{gathered}
$$

The objective function can be divided into income and cost. As for the income, it consists of income generated from the tickets and the consumption of passengers on board. However, passengers from different countries and regions outline considerable differences in their consumption levels and habits. Therefore, this last data is of low relevance and does not take a large proportion when compared to the ticket income. Thus, this part of the revenue will not be considered. The calculating process is as follows:

$$
\begin{gathered}
R_{s}=P_{s}+Q_{s} \\
P_{s}=f\left(\sum_{s=1}^{s} A_{s}, d_{s}, c_{p i}\right)=k_{1} \cdot \sum_{s=1}^{s} A_{s}+k_{2} \cdot d_{s}+\sum_{i} c_{p i} \cdot \sum_{j} x_{i j}+k_{3} \\
A_{s}=\sum_{i} a_{i} \cdot \sum_{j} x_{i j}
\end{gathered}
$$


During the calculation, $k_{i}(i=1,2,3)$ is a constant coefficient of a regressive solution. The ticket price $P_{s}$ and cruise route products requirements $Q_{s}$ are mainly obtained by a regression analysis. In most cases, the data is derived from the existing route of the market and the relevant data obtained from the interview. Also, the ticket pricing and the voyage costs have a close relevance and impact. According to the service providers' interviews, the industry practices and principles of the cruise ticket's pricing are "getting close to" the cruise total operating costs. Therefore, the costs mainly consist of the cost of fuel, port charges, tourism costs, etc. The formula (10) reflects the correlation among the ticket fare $P_{s}$ and the voyage distance $d_{s}$ (directly affect the fuel costs), the port fees $c_{p i}$ and other operation cost correlation.

The attractiveness of a route affects the price of that same route. In this paper, the general appeal of a route is also one of the factors that affects the price of airline routes, for instance. Also, the people's demand of the voyage conditions the ticket pricing and travel time. Nevertheless, according to a number of cruise company annual reports, we found that the cruise routes are able to guarantee a fully-booked cabin, or even a cabin that exceeds its limit. Thus, in view of these special market demands, this paper conveys that the demand for $Q_{s}$ is determined to be a fixed value $D$, showing the route assuring a full cabin travel.

On the other hand, the voyage cost consists of fuel cost $C_{s}^{o}$, port charge $C_{s}^{h}$, living cost $C_{s}^{l}$ and voyage operating cost $C_{s}^{F}$.The operating cost in voyage, such as the staff wage and marketing, is also relevant to voyage time. However, the daily costs can solely be known in the cruise companies' annual reports. Therefore, this is regarded as a fixed cost. The rest of the cost is considered as a variable one. As the port of call is supposed to provide the fuel and other materials efficiently, in most cases, cruise companies strive to choose the port which has the minimum fuel cost. Furthermore, the living cost refers to the accommodation, restaurants, fresh water and so on, all depending on the number of passengers and also the voyage time. Finally, the operating cost consists of staff wages, marketing costs, as well as the commission of travel agencies and sale agents.

$C_{s}=C_{s}^{F}+C_{s}^{V}$ represents the aggregate voyage cost, which consists of fixed cost and variable cost. $C_{s}^{F}=C_{f} \cdot T_{s}$ represents the fixed cost as the product of daily operating cost and voyage time. $C_{s}^{F}=C_{s}^{o}+C_{s}^{h}+C_{s}^{l}$ represents the fixed overall cost consisting of fuel costs, port charges and the living cost. $C_{s}^{o}=c_{r 1} \cdot \frac{T_{s}^{s}}{24}+c_{r 2} \cdot \frac{T_{s}^{t}}{24}+c_{c} \cdot \frac{T_{s}^{s}}{24}$ represents the consumed fuel in the voyage and docking. $C_{s}^{l}=c_{l} \cdot Q_{s} \cdot \frac{T_{s}}{24}$ represents the living cost. $C_{s}^{h}=\sum_{i} c_{p i} \cdot \sum_{j} x_{i j}$ represents the total port charges.

\section{CASE ANALYSIS}

In this paper, with regards to China as the home-port, a case analysis of routes in South Asia is outlined. In order to classify the rank, the evaluated object, data and information should be selected and arranged. The relevant data below is based on the existing market and the interview of cruise industry services, which are of great liability and value. The rank is given in Table1. 


\begin{tabular}{|c|c|c|c|}
\hline Country & Comprehensive competitiveness of port & Comprehensive rating score & Rank \\
\hline \multirow{4}{*}{ China } & Shenzhen & 2.8591 & 1 \\
\cline { 2 - 4 } & Shanghai & 2.8529 & 2 \\
\cline { 2 - 4 } & Sanya & 2.7276 & 4 \\
\hline \multirow{4}{*}{ Vietnam } & Xiemen & 2.7294 & 3 \\
\cline { 2 - 4 } & Hai phong & 2.3585 & 2 \\
\cline { 2 - 4 } & Vung tau & 2.1373 & 4 \\
\cline { 2 - 4 } & Da nang & 2.4214 & 3 \\
\hline \multirow{3}{*}{ India } & Nha trang & 2.2405 & 1 \\
\hline \multirow{3}{*}{ Malaysia } & Kolkata & 2.3797 & 2 \\
\cline { 2 - 4 } & Nhava sheva & 2.3142 & 3 \\
\cline { 2 - 4 } & Klang & 2.5313 & 1 \\
\cline { 2 - 4 } & Penang & 2.5907 & 2 \\
\hline \multirow{2}{*}{ Indonesia } & Kuantan & 2.3102 & 1 \\
\cline { 2 - 4 } & Langkawi & 2.5413 & 1 \\
\hline Sri Lanka & Jakarta & 2.7208 & 2 \\
\hline
\end{tabular}

We listed 17 different ports from 6 countries. Because of the large data scale, we solved the optimal routes by a large scale random solution of the optimal algorithm. Furthermore, for the highest-scoring ports of every country mentioned above, we could solve all the practical routes and optimal routes by traversal for the optimal algorithm.

\subsection{Basic data}

\section{(1)Ship type}

In China, the majority of the consumers are middle aged and elderly people who have both cash and leisure time. Thus, the Costa Atlantica of Costa Cruises is chosen due to its popularity in China, and in order to conduct the model in the most practical way possible. This type of ship has an average passenger capacity and tonnage in China, and is a convenient illustration. The gross tonnage of this ship is 85619tons. The seating capacity is 2680. The length is 292. The average speed is 22 knots.

The length and gross tonnage determine the ship's arrival and docking at the port. Also, the speed determines the voyage time. The seating capacity illustrates the maximum passenger capacity which, indirectly, affects the income. Moreover, the width and age are not considered in this model as their effect here is insignificant.

\section{(2)Operating cost}

The operating cost is extracted from the fixed cost and the variable cost. We have analyzed the annual reports and financial data of CARNIVAL Corporation, in the last 5 years. It was outlined that the two major data sources are the living cost in the cruise, and the fixed operation cost of the cruise. The living cost is a variable, and thus, we calculated that the average living cost of passengers is 53.1127 dollars per capita per day. On the other hand, the fixed operating cost is directly affected by the voyage time of duration. In view of this, we calculated that the fixed operating cost of ship is 2188.3983 dollars per voyage.

\section{(3)The regression equation of ticket prices}


Also, we analyzed the data showing the ticket prices of the Costa Atlantic departing China in 2015, by interviewing Costa Corporation. For the simple cruise routes, we chose the average price in calculation.

Table 2. The ticket price of Costa Atlantic

\begin{tabular}{|c|c|c|c|c|}
\hline Routes & Distance/sea mile & Port charge/\$ & Route attractiveness & Price/\$554.08 \\
\hline Tianjin-Jeju-Nagasaki-Tianjin & 1544.13 & 69.13 & 8.32 & 538.69 \\
\hline Tianjin-Jeju-Fukuoka-Tianjin & 1511.74 & 69.13 & 7.91 & 538.69 \\
\hline Tianjin-Jeju-Fukuoka-Tianjin & 1511.74 & 69.13 & 7.91 & 507.90 \\
\hline Tianjin-Jeju-Fukuoka-Tianjin & 1511.74 & 69.13 & 7.91 & 538.69 \\
\hline Tianjin-Busan-Fukuoka-Tianjin & 1935.88 & 69.13 & 7.85 & 584.88 \\
\hline Tianjin-Inchon-Tianjin & 856.44 & 34.33 & 5.52 & 383.73 \\
\hline
\end{tabular}

Source: http://cruise.ctrip.com \& BLM-Shipping

As seen from the above analysis, it can be concluded that the price of the cruise ticket is of a close proximity to the total operational cost consisting of the fuel cost, port charge and living cost. In all of these, the market requirement plays a significant role. Thus, in this paper, we eliminate the data of the ticket price and the corresponding data of route attractiveness, while normalizing the data with log function and formulate a multiple linear regression to obtain the expression as follows:

$$
P_{s}=0.0597 d_{s}^{s}+33.4584 A_{\text {total }}+C_{s}^{h}+114.4515
$$

\section{(4)Fuel prices}

The cruise ship heavily consumes the heavy oil during its navigation. As for docking, it consumes both the heavy oil and light oil, but this consumption is considerably less than that used in the navigation. After calculating, we assume that the price of heavy oil IFO380cst is $180 \$ /$ Ton, and that of light oil MDO is 360\$/Ton. The speed of cruise ship is 22 knot and thus the consumption of oil is 150 tons per day. Therefore, we can assume that, as the ship has a similar deadweight ton as a cruise, it will possibly consume 3.5 ton of heavy oil and 0.2 ton of light oil during the docking.

(5)The distance of alternative ports and the port charge

After surveying the port charge on the port authority's website, when the fuel cost and aggregate operating costs are compared, it can be seen that the difference of the port charge has a limited input to the revenue of the whole voyage. The table below shows the combinations of port charge data in different countries.

Table 3. Distance (sea miles) and charges (dollars) of small ports

\begin{tabular}{|c|c|c|c|c|c|c|c|}
\hline & Shenzhen & Da Nang & Penang & Benoa & Calcutta & Colombo & Port charges(\$) \\
\hline Shenzhen & 0 & 543.01 & 1823.22 & 2065.93 & 3075.24 & 3035.86 & 60651.0013 \\
\hline Da Nang & 543.01 & 0 & 1370.72 & 1824.26 & 2622.75 & 2583.36 & $27442.9572+2 Q_{s}$ \\
\hline Penang & 1823.22 & 1370.72 & 0 & 1293.44 & 1321.06 & 1283.46 & $8589.1808+1.9707 Q_{s}$ \\
\hline Benoa & 2065.93 & 1824.26 & 1293.44 & 0 & 2545.47 & 2441.26 & $26262.885+0.8 Q_{s}$ \\
\hline Calcutta & 3075.24 & 2622.75 & 1321.06 & 2545.47 & 0 & 1099.42 & $35737.5055+8.599 Q_{s}$ \\
\hline Colombo & 3035.86 & 2583.36 & 1283.46 & 2441.26 & 1099.42 & 0 & $12833.932+5.5 Q_{s}$ \\
\hline
\end{tabular}

Source : BLM-Shipping \& http://www.jiaotongjie.com \& http://www.tariffauthority.gov.in/ 
The port charge consists of the fixed and variable charges. The fixed charge consists of the pilotage dues, tug fee, harbor dues, quarantine fee, berthing fee, mooring fee, shipping fee and so on. The charging standard of these varies according to each country. On the other hand, the variable charge is calculated on the number of passengers boarding and going ashore. Moreover, the fixed data of the port charge mentioned above is calculated in the 6 hours of docking time.

\subsection{The analysis on the small-scale traverse of the optimal route}

In order to design the simulation program, this paper examines the number of port of calls by MATLAB. The results are shown in Table 4.

Table 4. The results of the analysis on small-scale traverse of the optimal route

\begin{tabular}{|c|c|c|c|}
\hline $\begin{array}{c}\text { The number of } \\
\text { port of call }\end{array}$ & 1 port of call & 2 ports of call & $\begin{array}{c}3-6 \text { ports } \\
\text { of call }\end{array}$ \\
\hline Optimal routes & Shenzhen - Colombo - Shenzhen & $\begin{array}{c}\text { Shenzhen - Benoa }- \\
\text { Da Nang -Shenzhen }\end{array}$ & - \\
\hline Distance & 6071.72 sea miles & 4433.20 sea miles & - \\
\hline Attractiveness & 5.35 & 8.02 & - \\
\hline Duration & 12 days & 9.15 days & - \\
\hline $\begin{array}{c}\text { Port Charges per } \\
\text { passenger }\end{array}$ & $\$ 32.92$ & $\$ 45.47$ & - \\
\hline Supposed ticket price & $\$ 688.27$ & $\$ 691.25$ & - \\
\hline Total Revenue & $\$ 1844575.28$ & $\$ 1857728.53$ & - \\
\hline Total cost & $\$ 2146500.08$ & $\$ 1690715.27$ & - \\
\hline Profit & $\$-301924.81$ & $\$ 167013.27$ & Not practical \\
\hline Practical or not & Not practical & Practical & \\
\hline
\end{tabular}

In 1 port of call, the profit is in the negative as seen above, unlike the voyage cost, fuel cost per voyage, port charges per voyage and total voyage income. The same data is again shown in Tab 6. It can be seen that the living cost of passengers takes a large proportion of the total cost. If the voyage lasts longer, the living cost correspondingly increases. In the optimal scheme, the voyage time lasts for 12 days but has only 1 port of call, which is not the most reasonable or practical cruise route to plan.

Table 5. The cost analysis on having 1 port of call

\begin{tabular}{|c|c|c|}
\hline & Cost & Proportion \\
\hline Total cost & 2146500.08 & - \\
\hline Fuel cost & 310485.6818 & $14.46 \%$ \\
\hline Port charges & 88224.93 & $4.11 \%$ \\
\hline Living cost of passengers & 1721529.85 & $80.20 \%$ \\
\hline Voyage duration & \multicolumn{2}{|c|}{12} \\
\hline
\end{tabular}

In 3-6 ports of call, according to these simulation results, it seems impossible to meet the constraints of time window, arriving at the port at 6:00 18:00 and departing at 12:00 23:00, no matter how we adjust the ports order. Thus, once again, if there are 3-6 port calls, it is still not a practical route.

Based on this analysis, it can be concluded that when Shenzhen Taiziwan cruise home-port, having a high construction level, is regarded as the port of departure as well as the port of destination, there would be 1 or 2 port calls. Here, the route will meet the constraints of the time window. However, if one has 2 port calls, the cruise company will gain profit. On the 
other hand, having 3-6 port calls will lead to a long voyage, and so, there will be no constraints. Thus, as one can see, choosing ports based on attractiveness in different countries may not be the best scheme.

\subsection{The analysis on large-scale traversal solution}

This paper also sorts out the distance and port charges of 17 ports. Because of having a large calculation scale, we used the random algorithm as a solution to the problem. Although this cannot work in comparison to all schemes, it is a better way of formulating the voyage scheme and designing the optimal route.

Table 7. The results of analysis on small-scale traverse the optimal route

\begin{tabular}{|c|c|c|c|c|c|c|}
\hline $\begin{array}{c}\text { The number } \\
\text { of } \\
\text { port of call }\end{array}$ & 1 port of call & $\begin{array}{c}2 \text { ports of } \\
\text { call }\end{array}$ & 3 ports of call & 4 ports of call & 5 ports of call & $\begin{array}{l}\text { More than } 5 \\
\text { ports of call }\end{array}$ \\
\hline $\begin{array}{l}\text { Optimal } \\
\text { routes }\end{array}$ & $\begin{array}{l}\text { Shenzhen - } \\
\text { Vung tau - } \\
\text { Shenzhen }\end{array}$ & $\begin{array}{c}\text { Shenzhen - } \\
\text { Kuantan - } \\
\text { Shenzhen }\end{array}$ & $\begin{array}{l}\text { Shenzhen - } \\
\text { Kuantan - } \\
\text { Nha trang - } \\
\text { Hai phong - } \\
\text { Shenzhen }\end{array}$ & $\begin{array}{c}\text { Shenzhen - } \\
\text { Kuantan - } \\
\text { Penang - } \\
\text { Danang - } \\
\text { Vung tau- } \\
\text { Shenzhen }\end{array}$ & $\begin{array}{c}\text { Shenzhen - } \\
\text { Langkawi - } \\
\text { Danang - } \\
\text { Vung tau - } \\
\text { Kuantan - } \\
\text { Hai phong - } \\
\text { Shenzhen }\end{array}$ & $\begin{array}{c}\text { It is } \\
\text { impossible to } \\
\text { solve the } \\
\text { practical } \\
\text { scheme to } \\
\text { meet the } \\
\text { constraints of } \\
\text { voyage time } \\
\text { and time } \\
\text { window of } \\
\text { different } \\
\text { ports }\end{array}$ \\
\hline Distance & 1796.52 & 2685.06 & 3187.08 & 4647.96 & 6145.49 & - \\
\hline Attractiveness & 5.99 & 7.41 & 9.77 & 12.32 & 14.63 & - \\
\hline Duration & 3.90 & 5.84 & 7.04 & 10.05 & 13.14 & - \\
\hline $\begin{array}{l}\text { Port Charges } \\
\text { per passenger }\end{array}$ & 34.87 & 40.05 & 52.29 & 57.46 & 69.70 & - \\
\hline $\begin{array}{c}\text { Supposed } \\
\text { ticket price }\end{array}$ & 423.83 & 562.84 & 683.99 & 861.78 & 1003.73 & - \\
\hline $\begin{array}{c}\text { Total } \\
\text { Revenue }\end{array}$ & 1135865.93 & 1508417.30 & 1833087.77 & 2309568.00 & 2789212.01 & - \\
\hline Total cost & 762851.77 & 1108263.61 & 1347039.63 & 1878386.64 & 2440572.38 & - \\
\hline Profit & 373014.16 & 400153.68 & 486048.14 & 431181.36 & 348639.62 & - \\
\hline $\begin{array}{c}\text { Practical or } \\
\text { not }\end{array}$ & Practical & Practical & Practical & Practical & Practical & Not practical \\
\hline
\end{tabular}

\section{SUMMARY}

Overall, in this paper, the model simulated the voyage of which duration lasts for 4-14 days. However, the main cruise routes in the market at present are the short routes which last for 3-4 days, the medium routes which last 6-8 days, and the long routes which last more than 8 days. Thus, this model can be considered as practical to all kinds of cruise companies, which all offer great contributions to manufacturing diverse cruise products and consequently increasing the market potential. Although we took various positive factors into consideration, there are also some drawbacks.

First of all, this model does not refer to the time difference, so it is not suitable for global routes. Secondly, this paper does not take the seasonal factor into consideration. One route 
cannot work for all the four seasons each year. So, this paper simulates a substantial number of general routes. Moreover, the routes are changeable for cruise companies. They can also refer to this research, make permutation and combination of all routes in their further operation. Thirdly, it adds more information to the model, helping it increase and enhance its accuracy. Fourthly, in this paper we did not refer to the mode of "Fly+Cruise". This mode refers to how the passengers start their journey from home, arrive at the cruise home-port by other vehicles and finish the whole voyage in the end. For those visitors who do not start their journey at the home-port, it would be helpful to think about how they get to the home-port. Furthermore, these transportation costs of the passengers arriving at the home-port will be settled in the revenue management, making the model all the more practical.

\section{Acknowledgments}

National Natural Science Foundation of China (71272219, The network attribute of logistics service supply chain and its mechanism to core enterprise growth)

\section{References}

Rodrigue J P, Notteboom T. (2009) 'The cruise industry', [Online], Available: http://people.hofstra.edu/geotrans/eng/ch7en/appl7en/ch7a4en.html [5 July 2017].

Mulder, J., \& Dekker, R. (2014). Methods for strategic liner shipping network design. European Journal of Operational Research, 235(2), 367-377.

Brouer, B. D., Desaulniers, G., Karsten, C. V., \& Pisinger, D. (2014). A matheuristic for the liner shipping network design problem with transit time restrictions. Transportation Research Part E, 72(C), 42-59.

Dong, J. X., Lee, C. Y., \& Song, D. P. (2015). Joint service capacity planning and dynamic container routing in shipping network with uncertain demands. Transportation Research Part B Methodological, 78, 404-421.

Aversa, R., Botter, R. C., Haralambides, H. E., \& Yoshizaki, H. T. Y. (2005). A mixed integer programming model on the location of a hub port in the east coast of south america. Maritime Economics \& Logistics, 7(1), 1-18.

Karsten, C. V., Pisinger, D., Ropke, S., \& Brouer, B. D. (2015). The time constrained multi-commodity network flow problem and its application to liner shipping network design. Transportation Research Part E Logistics \& Transportation Review, 76, 122-138.

Barron, P., \& Greenwood, A. B. (2006). Issues determining the development of cruise itineraries: a focus on the luxury market. Tourism in Marine Environments, 3(2), 89-100.

Johnson, D. (2006). Providing ecotourism excursions for cruise passengers. Journal of Sustainable Tourism, 14(1), 43-54.

Lekakou, M. B., Pallis, A. A., \& Vaggelas, G. K. (2009). Which homeport in europe: the cruise industry's selection criteria. Tourismos An International Multidisciplinary Journal of Tourism, 4(4), 1 - 5. 
Lorenzo Gui, \& Antonio Paolo Russo. (2011). Cruise ports: a strategic nexus between regions and global lines-evidence from the mediterranean. Maritime Policy \& Management, 38(2), 129-150.

Demirel, N. C., \& Yucenur, G. N. (2011). The cruise port place selection problem with extended vikor and anp methodologies under fuzzy environment. Lecture Notes in Engineering \& Computer Science, 2191(1), 1300-1306. 